\title{
EV SİNEMASI TASARIMINDA HACİM AKUSTİĞİ
}

\author{
Neslihan GÜZEL*, Sercem Murat SAĞIN** \\ * Dokuz Eylül Üniversitesi, Mimarlık Fakültesi, Mimarlık Bölümü, Tnnaztepe Kampusu, 35160 Buca/İzmir. \\ ** Özel Șirket, Cumhuriyet Bulvarı, No:26/505, Konak/İzmir. \\ neslihan.guzel@deu.edu.tr, smsagin@hotmail.com
}

(Geliş/Received: 21.06.2011; Kabul/Accepted: 15.05.2014)

ÖZET

Günümüzde birçok insanın, ev ortamında sinema keyfini yaşamak istediği bir gerçektir. Ev sineması sistemleri, sinema teknolojisinin gelişimine bağlı olarak evlerimizde de kullanılmaya başlanmıştır. Bu çalışma, evlerde arzulanan ideal sinema ortamının özelliklerini belirlemek için yapılan bir araştırmayı içermektedir. Ev sinema sistemlerinin gereksinimlerini belirlemek için mevcut örnekler üzerinde yapılan ölçüm ve değerlendirmeler ile ev sineması mekânlarının akustik konfor şartları araștırılmıștır. Sonuç olarak incelenen örneklerde ev sineması için mekânsal açıdan gerekli akustik şartların sağlanmadığı ve bu gereksinimlerin elektronik ekipmanlar aracılığı ile karşılandığı anlaşılmıştır.

Anahtar kelimeler: Ev sineması, Hacim akustiği, Çınlama süresi.

\section{ROOM ACOUSTICS IN HOME THEATRE DESIGN}

\begin{abstract}
It is a fact that, nowadays lots of people want to get the pleasure of cinema at their homes. Home theatre systems are beginning to be used in our homes by the development of cinema technologies. This study is intended for determining properties of the ideal cinema spaces desired in homes. Acoustical comfort conditions of spaces were investigated with measurements and evaluations in order to determine the requirements of home theatre systems. As a result samples examined in this study for home theater acoustic and spatial conditions are not provided and these requirements are substituted through means of electronic equipment.
\end{abstract}

Keywords; Home theatre, Room acoustics, Reverberation time.

\section{GÍRISŞ (INTRODUCTION)}

Günümüzde yoğun iş temposu, șehir şartları, ekonomik sorunlar vb. gibi sebeplerden dolay1 sinemaya gidilememesi sebebiyle geliştirilen ve ev ortamının rahatlığı gibi avantajları da yanında taşıyan ev sinema sistemlerine talep giderek artmaktadır. Akustik açıdan ev sinemaları sinema salonlarından farklı olarak düşünülmemelidir. Ev sinema mekânları, sinema salonları ile aynı akustik tasarım mantığına sahip ancak daha küçük hacimli ve ekonomik mekânlardır. Bu nedenle ev sineması mekânlarında akustik açıdan özel önlemlerin alınması gerekmektedir.

Eğer karşılaştıracak olursak, ev sinemalarında hoparlörlerden çıkan sesin dinleyiciye ulaşma süresi daha kısa olduğu için çevreleyen ses-surround sound hoparlörlerinin yerleşimi sinema salonlarına göre daha zor ve kritiktir [1].

Ayrıca küçük hacimli bu mekânlar yoğun ve eşdeğer şekilde ses yutucu malzemelerle donatılmadıklarında, sesin mekân içinde yankılanmasına neden olabilirler. Diğer bir deyişle, küçük hacimli bu mekânlarda yansıma ve rezonans nedeniyle sesin yayılmasını önlemek amacıyla mekânın tüm yüzeylerinde sesi yutan yada yayan akustik amaçlı ses yalıtım çözümleri uygulanmalıdır [2].

\section{1 Çalışmanın Amacı ve Kapsamı (Aim and Scope of} the Study)

Bu çalışmanın amacı, küçük kapalı mekânlar olarak değerlendirilen ev sinemalarının akustik ve elektronik sistemlerinin incelenerek, örnek odalarda yapılan 
ölçümlemeler doğrultusunda bu mekânların akustik niteliklerinin değerlendirilmesidir.

\section{2 Çalışmanın Yöntemi (Method of the Study)}

Bu çalışmada, mevcut örnekler arasından farklı mekân boyutu, geometrik biçim, kullanılan malzeme ve ekipman nitelikleri nedeni ile üç örnek seçilmiştir. Bu üç farklı örneğin mekânsal analizi yapılarak ve bu hacimlerde kullanılan yer, duvar, tavan kaplamaları vb. özellikleri irdelenmiştir. Yapılan deneysel çalışmada, çınlama süreleri ölçülmüş ve elde edilen sonuçlar, Dirac akustik yazılımı ile sayısal verilere dönüştürülmüştür. Yazılımdan elde edilen ISO 3382 kriterlerine göre mekânların çınlama sürelerini veren RT60, erken sönüm zaman1-early decay time (EDT), T20 ve T30 değerleri tablolar ve grafikler aracılığı ile değerlendirilerek mekânların akustik nitelikleri irdelenmiştir.

Ölçüm yapmak amacıyla çeşitli ekipmanlardan yararlanılmıştır. Bu ekipmanlar; veri depolamak ve kullanmak amaciyla bir diz üstü bilgisayar, ses kayıtlarını aktarmak için bir harici-external ses kartı, ses kayıtlarını almak için çok yönlü mikrofon ve Dirac akustik yazılımıdır. Ani ses kaynağı olarak oyuncak balon seçilmiştir. Ölçümlerde, ISO 3382'ye uygun olarak alıcı yüksekliği 1,20 $\mathrm{m}$ ve kaynak yüksekliği 1,50 m alınmıştır [3].

\section{EV SINEMASI KAVRAMI (THE CONCEPT OF HOME THEATRE)}

Ev sinemaları günümüzde sinema konforunu ev ortamına taşıyacak koşulların oluşturulması olarak tanımlanabilir. Başka bir ifade ile görüntü ve ses kriterleri, sinema temel tasarım prensipleri, aydınlatma, koltuk düzeni ve akustik gereksinmeleri tam olarak sağlanmış bir sinema salonunun ölçeğinin küçültülerek aynı mantık çevresinde ev ortamına adaptasyonu olarak açıklanabilir.

Ev sinemaları için ses kaynakları ve yerleşimi, oda boyutları ve yerleşimi, temel yerleşim prensipleri, oturma düzeni, görüntü perdesi, görüntü kaynağ1, boyutları ve yerleşimi, akustik detaylar ve çözümler ve aydınlatma gerekli temel koşullar olarak sıralanabilir. Bu koşullar gerçek anlamda bir sinema ortamının eve taşınmasını sağlar. En basitinden en karmaşığına kadar tüm ev sinemalarında uyulması gereken kurallar kadar kullanılan donanımlar da önemlidir.

Ev sinema sistemlerinde kullanilan elektronik donanımlar; görüntü kaynağı, $\mathrm{A} / \mathrm{V}$ alıc1-receiver, hoparlörler, bas hoparlör-subwoofer ve görüntü perdesidir.

\subsection{Ses Formatları (Audio formats)}

Dijital ses teknolojilerinin gelişmesi sinema ortamlarının evlerimize daha kolay adapte olmasını sağlamış bunun da ötesinde sadece ev sinemaları için ses teknolojileri geliştirilmeye başlanmıştır. Çevreleyen ses-surround sound, ses yapılanmalarının üçüncü dönemidir. Sadece ses üretmenin amaçlandığ 1 ilk dönem 1800'lü yılların son dönemlerinden 1950'lere kadar sürmüştür. Temelleri 1930'lara dayanan fakat gündelik hayata ancak 1950'lerin ortasında giren stereo'nun geliştirilmesi ile de ikinci dönem başlamıştır [4]. $\mathrm{Bu}$ dönemin gelişmeleri, 'dinleme keyfi'ni birkaç kat arttırmanın ve doğal sese daha yakın bir tını yakalayabilmenin yanı sıra sesin yeniden üretimine iki boyut kazandırmıştır. Bunlar; sesin yatay düzlemde belli açlarla konumlandırılabilmesi ve buna bağlı olarak yapılan kayıta 'alan derinliği'nin katılmış olmasıdır. Bu iki boyut, stereonun "sahne/ses imajı" adı verilen özelliğinin temelini oluşturmaktadır [4].

Çevreleyen sesin gelişimini; 'tek boyutlu', 'iki boyutlu' ve 'üç boyutlu' evreler olarak sınıflayabiliriz. İlk iki evrede sinema, TV ve müzik endüstrisi birçok açıdan birbirinden tamamen ayrı iken üçüncü evre ile birlikte bu endüstriler birbirleriyle entegre olarak çalışmaya başlamışlardır [5].

\subsection{1 Çevreleyen Ses (Surround Sound)}

'Sesin birbirinden bağımsız dört ya da daha fazla kanaldan dolayısıyla her kanal için ayrı bir hoparlörden gelmesi' çevreleyen sesin-surround sound en kısa ve temel tanımıdır (Şekil 1) [6].

En basitinden en karmaşığına kadar çevreleyen ses formatlarının tümünde ses, birbirinden bağımsız kanallar olarak kopyalanmıştır. İlk çevreleyen ses formatı dört kanal ile yola çıkmıştır.

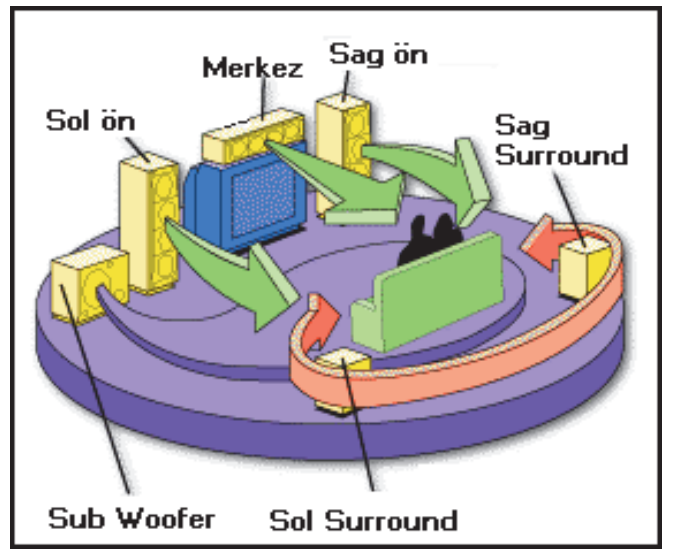

Şekil 1. Ev sineması temel dağılım planı [6] (Basic distribution plan of home theatre) 
Tüm çevreleyen ses formatlarında temel prensip; dinleyici/izleyicinin önünde konumlanan ve diyalogların kısmen de müziğin verildiği 'merkez kanal', ağırlıklı olarak müziğin kısmen efekt ve diyalogların yer aldığı 'ön sağ ve sol kanallar' ile atmosferin etkisini yaratan, dinleyici/izleyicinin yanında ve/veya arkasında yer alan 'efekt kanalları'dır. Buna ek ve tercihe bağlı olarak da sadece alçak frekans seslere ayrılmış ve ambiyans etkisini artıracak bir alçak frekans kanalı da sistemde yer alabilmektedir.

Merkez hoparlör-center speaker: Orta sesleri yani insan seslerini kontrol eden birincil hoparlördür. Ön hoparlörler-front speakers: Ana ses kontrolünü sağlayan ana hoparlörlerdir. Arka hoparlörler-rear speakers: Arka sesleri yani efektlerin büyük bölümünü sağlayan hoparlörlerdir. Bas hoparlörsubwoofer speaker: Ana bas sesleri ve bas ağırlıklı efektler ile derin basları algılamamızı sağlayan hoparlörlerdir (Şekil 1).

Temel beş hoparlörlü sistemlerde yer alan ön, arka hoparlörler duyulabilir. Bu hoparlörler geniş bantta (ortalama 30-40 Hz'den başlayıp, $30 \mathrm{KHz}$ lere kadar çıkan frekans yansımalarıyla) çalışırlar. Bas sesleri sağlayan bas hoparlör-subwoofer denilen ve ".1 ve +1 " diye ifade edilen ses kaynağ 1 ise daha dar bir frekans aralığında çalışmaktadır.

Günümüz sinemalarında Dolby Laboratories'in geliştirdiği (Dolby Digital) , Digital Theater Systems' in geliştirdiği (DTS), ve Sony'nin geliştirdiği Sony Digital Dynamic Sounds (SDDS) formatları kullanılmaktadır. Bunların yanında THX (Thomas Holman's Expreriments) denilen ancak bir ses formatından farklı bir kalite standardı olan bir standart da günümüz sinemalarında kullanılmaktadır [7].

\subsection{Ev Sineması Tasarımında Mekân Boyutları ve Geometrisinin Hacim Akustiği ile İlişkisi (Geometry and Space Dimension relationships with Room Acoustics in Home Theatre Design)}

Maksimum ses yayılımını sağlamak için tasarlanan mekân geometrisinin hacim akustiğine etkisini kavrayabilmek amacıyla birçok deneysel çalışma yapılmıştır. Bu alanda deneysel olarak desteklenmiş çok sayıda görüş vardır [8].

Mekân geometrileri kare, dikdörtgen, silindirik, küresel ya da çokgen yüzeylerden oluşabilir. İçbükey yüzeylere sahip mekânlarda keskin odak noktaları veya yoğunlaşmış odak noktaları oluşabilmektedir. $\mathrm{Bu}$ nedenle parabolik yüzeyler, silindirik ve küresel geometriler tercih edilmez. 4, 5, 6 ve 8 yüzeyli daireye yakın konkav yüzeylerde de yoğunlaşmış odak noktaları ortaya çıkabilmektedir [8]. Bu konuda yapılan çalışmaların tamamı, en ideal oda boyutlarını bulmaya yöneliktir. Sepmeyer 1965 yılında yaptığı çalışmalar sonucunda belirlediği oranları yayınlamıştır [8]. Louden tam 125 oda oranı belirlemiş ve bu oranlarda yapılırsa başarılı sonuçlara ulaşılacağını iddia etmiştir [8]. Volkmann'ın 2:3:5 oranı uzun yıllar ideal oda oranı olarak görülmüştür. Boner ise 1:1,26:1,59'luk bir oran yayınlamıştır. Bu oran günümüzde oldukça kabul görmektedir (Tablo 1) [8].

Küçük hacimli mekânların akustik özelliklerini değerlendirme kriterleri modal rezonanslar ve çınlama süreleridir. Modların yayılım düzensizliği ve modların rast gelmesi potansiyel bir problemdir. Üst üste gelen modlar, rezonans sorunu yaratırlar. Tablo 1'de görüldüğü gibi, bu belirlenen oranlara göre oluşturulan odalarda yapılan araştırmalar sonunda bazı frekanslarda rezonans oluştuğu görülmektedir. Bir sinema mekânı tasarımında her ne kadar mükemmeli yakalamak zor olsa da yapılacak ilk adım Tablo 1'de verilen oranlar göz önünde bulundurularak uygun oda boyutlarını belirlemek olmalıdır. Çınlama süresi RT60, bir odanın hacmi ile doğrudan, odada kullanılan malzemelerin yutuculuğu ile ters orantılıdır. Bunun anlamı, odanın boyutu arttığında çınlama süresi artmakta ve oda yüzeylerindeki yutuculuk azalmaktadır. Diğer bir deyişle odanın boyutu azaldığında çınlama süresi azalmakta buna karşılık oda yüzeylerindeki yutuculuk artmaktadır. Bu nedenle çınlama süresini kontrol edebilmek için ya oda büyüklüğü değiştirilmelidir ya da odada kullanılan yutucu malzeme miktarı değiştirilmelidir [9].

Tablo 1. Önerilen belli başlı oda oranları [8] (Recommended main room rates)

\begin{tabular}{llllll}
\hline Geliştiren & & Yükseklik & En & Boy & Bolt alanı \\
\hline Sepmeyer & A & 1,00 & 1,14 & 1,39 & $(-)$ \\
& B & 1,00 & 1,28 & 1,54 & $(+)$ \\
& C & 1,00 & 1,60 & 2,33 & $(+)$ \\
\hline Louden & D & 1,00 & 1,4 & 1,9 & $(+)$ \\
En ideal 3 oran & E & 1,00 & 1,3 & 1,9 & $(-)$ \\
& F & 1,00 & 1,5 & 2,5 & $(+)$ \\
\hline Volkmann & G & 1,00 & 1,5 & 2,5 & $(+)$ \\
$2: 3: 5$ & & & & & \\
\hline Boner & H & 1,00 & 1,26 & 1,59 & \\
$1: \sqrt[3]{2}: \sqrt[3]{4}$ & & & & &
\end{tabular}




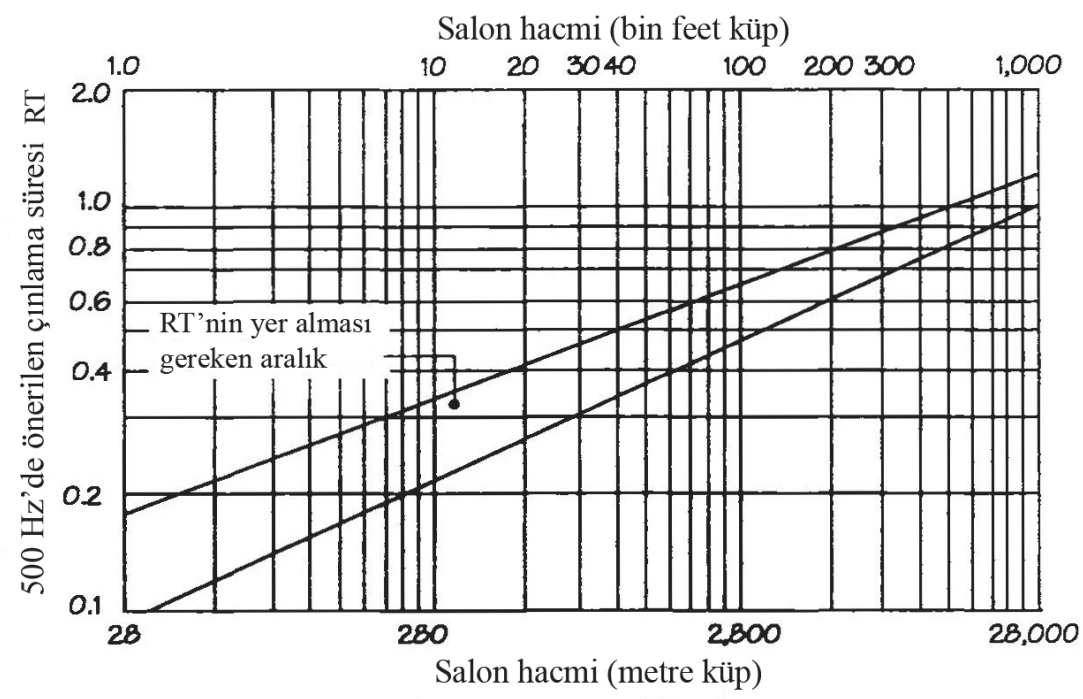

Şekil 2. Sinema salonları hacimlerine bağlı olarak önerilen 500Hz'deki çınlama süreleri [10] (Recommended reverberation time at $500 \mathrm{~Hz}$ versus Cinema Hall Volume)

Sinema salonları için düşük çınlama süresi elde edilmelidir. $\mathrm{Bu}$ amaçla salonun yüzeylerinde yutucu malzemeler kullanılmalıdır [10].

Sinema ekipmanları ile ilgili iki büyük girişimci olan Lucasfilm Ltd'ye ait THX gurubu, Dolby Laboratories ve diğer bir önemli bilgi kaynağı olan SMPTE (Society of Motion Picture and Television Engineers)'nin sinema salonları için önerdikleri standartlar neredeyse aynıdır. Bu standartlarda sinema salonları için önerilen çınlama süreleri hacme bağlı olarak verilmiştir (Şekil 2) [10] [11].

Şekil 2'de yer alan grafikte sinema salonlarının hacmine bağlı olarak $500 \mathrm{~Hz}$ de çınlama süreleri görülmektedir. Bu grafiğe göre, örneğin $50 \mathrm{~m}^{3}$ hacme sahip bir ev sineması mekânı için önerilen çınlama süresi $0,2 \mathrm{~s}$ civarındadır.

\section{EV SINEMASI ÖRNEKLERINDE ÇINLAMA SÜRESININ INCELENMESI (THE EXAMINATION OF THE REVERBERATION TIME ON HOME THEATRE SAMPLES)}

Ev sineması mekânlarında, tasarlanan mekânın yapısına göre akustik detayları da en baştan düşünülmesi gereklidir. Bu çalışma için seçilen ve mevcutta var olan üç odadan ikisi ev sineması amaçlı olarak yapılan ve bu işlevle kullanılan mekânlardır. Diğer üçüncü oda ise, ev ortamında aynı zamanda yaşam alanı olarak kullanılan ancak aynı zamanda sinema işlevi de kazandırılmış bir mekândır.

Ölçüm yapmak amacıyla çeşitli ekipmanlardan yararlanılmıștır. Bu ekipmanlar, veri depolamak ve kullanmak amaciyla bir diz üstü bilgisayar, ses kayıtlarını aktarmak için harici-external ses kartı, ses kayıtlarını almak için çok yönlü mikrofon ve Dirac akustik yazılımıdır. Ani ses kaynağı olarak oyuncak balon seçilmiştir. Alıcı noktası olarak çevreleyen hoparlörlerin-surround speakers ortasından dinleme noktasına yakın ve yerden 1,20 m yükseklikteki nokta seçilerek ölçümler yapılmıștır. Kaynak yüksekliği 1,50 m alınmıştır [3]. Alınan ses örnekleri Dirac akustik yazılımında sayısal sonuçlara dönüştürülmüş ve çınlama süreleri bulunmuştur.

\subsection{Ev Sineması Örnekleri (The Examples of Home Theatre)}

\subsection{1 "Oda 1" (Room 1)}

\subsubsection{Boyutsal ve geometrik analiz (Dimensional and} geometric analysis)

Mekân, ev sineması olarak sadece bu işlev için tasarlanmış bir demo odasıdır. İzmir'de sinema sistemleri satan bir firmanın iki demo odasından biri olan bu oda, birçok ses sisteminin test edilmesi için tasarlanmıştır. Bu işlevi dolayısıyla, mekân tamamen ev sineması hacim akustiği kriterlerine göre şekillendirilmeye çalışılmıştır. "Oda 1" hacim olarak dikdörtgen prizmasına yakın bir geometriye sahiptir. Plan düzlemi çok düzgün olmamakla birlikte ortalama olarak $3,10 \times 5,50 \times 2,65 \mathrm{~m}$ boyutlarına sahiptir. Toplam hacim ortalama $40 \mathrm{~m}^{3}$ 'tür.

Mekânda yer döşeme kaplaması olarak iki farklı malzeme kullanılmıştır. Bu kaplamalar mekânda kot farkıyla birbirinden ayrılmıştır ve düşük kotta $6,15 \mathrm{~m}^{2}$ ahşap parke, üst kotta $11,63 \mathrm{~m}^{2}$ halı kullanılmıştır. Duvarlarda kaplama malzemesi olarak $4 \mathrm{~cm}$ kalınlığında, $70 \mathrm{~kg} / \mathrm{cm}^{3}$ yoğunluğunda taş yünü levhalar tercih edilmiştir. Toplam $83,10 \mathrm{~m}^{2}$ duvar yüzey alanına sahip “Oda 1"in $36,80 \mathrm{~m}^{2}$ 'si taş yünü levhalar ile kaplıdır. Tavan kaplamasında ise mineral esaslı püskürtme sıva kullanılmıştır. Tavan yüzey alanı 26,26 m²'dir. Mekânda mobilya olarak iki kişilik bir deri koltuk bulunmaktadır (Şekil 3 ve Şekil 4) [12]. 
Tablo 2'de "Oda 1"de kullanılan malzemeler ve yutuculuk katsayıları yer almaktadır.

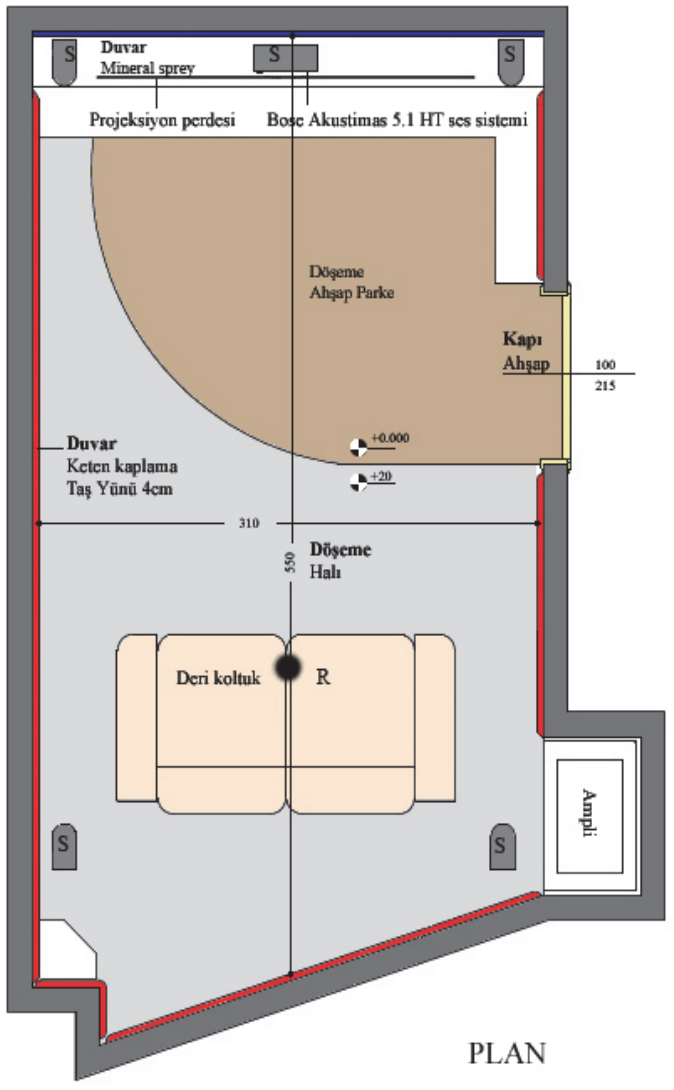

Şekil 3. "Oda 1"in planı [12] (The plan of Room 1)

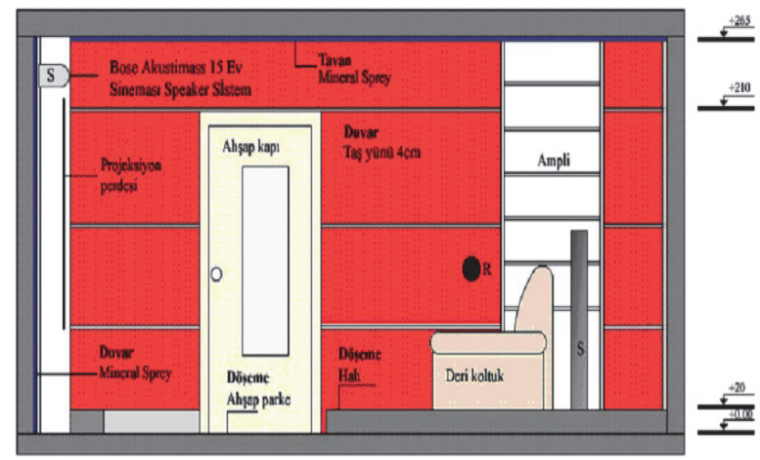

KESIT

Şekil 4. "Oda 1"in kesiti [12] (The section of Room 1)
3.1.1.2 "Oda 1"deki mevcut elektronik ekipmanlar (Existing electronic equipments at Room 1)

"Oda 1"de, 'klasik 5.1' denilen 6 kanaldan oluşan Bose Akustimass $15 \quad 5.1 \quad$ Home Theatre sistemi kullanılmıştır. Bu sistem 5 adet küp hoparlör (ön sağ, ön sol, merkez, 2 adet çevreleyen kanal) ve 1 adet bas hoparlörden oluşmaktadır. Her bir küp hoparlörde 2 adet $6,35 \mathrm{~cm}$ çapında Twiddler TM hoparlör mevcuttur. Bununla birlikte bas hoparlörde 2 adet 13 $\mathrm{cm}$ çapında hoparlör bulunmaktadır. $\mathrm{Bu}$ hoparlörün ayırıc1 özelliğini sahip olduğu bas hoparlör bünyesindeki amfiye ait bir modül oluşturmaktadır. Ayrıca çevreleyen hoparlörlerdeki hareket kabiliyeti mekândaki çevreleyen ses etkisini arttırmak için tasarlanmıştır. Ses sisteminde amplifikatör olarak DTS-ES Discrete/Matrix 6.1, DTS Neo:6, Dolby Digital EX, Dolby ProLogic II ses formatlarını destekleyen Onkyo TX SR501E alıcı kullanılmıştır. 6.1 kanal çevreleyen ses sistemine uygun olarak tasarlanmış, 6x85 W çıkış gücüne sahip bu alıcıda 4 $\mathrm{S}-\mathrm{Video}$ giriş ve 2 çıkış, 3 dijital giriş ( 2 optik/1 eş eksenli-coaxial) bulunmaktadir. Oynatıcı olarak Pioneer DV-525 DVD kullanılmıştır. Bu cihaz ikiz lazer manyetik teknolojisiyle üretilmiş, bileşik video çıkışlarda DVD/VCD/CD/CD-R özellikli formatlarla oynatma yeteneğine sahiptir. Cihazın örnekleme frekansı $96 \mathrm{KHz}, \mathrm{D} / \mathrm{A}$ dönüştürücüsü 24 bit çözünürlüktedir. DTS DVD dijital çıkışa sahiptir.

\subsubsection{3 Ölçüm sonuçları (Measurement results)}

"Oda 1" de yapılan deney sonucunda ölçümlenen frekanslara göre yazılımdan elde edilen sonuçlar Tablo 3 'te verilmiştir.

"Oda 1" de elde edilen RT60, EDT, T20 ve T30 çınlama süreleri-frekans grafiği Şekil 5'te gösterilmiştir.

\subsection{2 "Oda 2" (Room 2)}

\subsubsection{Boyutsal ve geometrik analiz (Dimensional and} geometric analysis)

Ev sineması işlevi için tasarlanmış olan "Oda 2", "Oda 1" gibi demo odası olarak kullanılmaktadır. "Oda 2" tam bir dikdörtgen plana sahip olmasa da, hacim olarak dikdörtgenler prizmasına yakındır.

Tablo 2. "Oda 1"de kullanılan malzemelerin yutuculuk katsayıları (The absorption coefficiency of materials in used for Room 1)

\begin{tabular}{|l|l|l|l|l|l|l|l|}
\hline Malzeme & $\mathbf{m}^{\mathbf{2}}$ & $\mathbf{1 2 5} \mathbf{~ H z}$ & $\mathbf{2 5 0} \mathbf{~ H z}$ & $\mathbf{5 0 0 ~} \mathbf{~ z z}$ & $\mathbf{1 0 0 0} \mathbf{~ H z}$ & $\mathbf{2 0 0 0} \mathbf{~ H z}$ & $\mathbf{4 0 0 0} \mathbf{~ H z}$ \\
\hline $\begin{array}{l}\text { Taş yünü 4 cm, } \\
70 \mathrm{~kg} / \mathrm{m}^{3}\end{array}$ & 36,80 & 0,20 & 0,75 & 0,90 & 0,85 & 0,90 & 0,85 \\
\hline Mineral sıva & 26,26 & 0,16 & 0,45 & 0,70 & 0,90 & 0,80 & 0,85 \\
\hline Halı & 11,63 & 0,02 & 0,06 & 0,14 & 0,37 & 0,60 & 0,65 \\
\hline Ahşap Parke & 6,15 & 0,04 & 0,04 & 0,07 & 0,06 & 0,06 & 0,07 \\
\hline Ahşap Kap1 & 2,26 & 0,14 & 0,10 & 0,06 & 0,08 & 0,10 & 0,10 \\
\hline Deri koltuk & 1,30 & 0,40 & 0,50 & 0,58 & 0,61 & 0,58 & 0,50 \\
\hline
\end{tabular}


Tablo 3. "Oda 1" in ölçümü sonucunda elde edilen RT60, EDT, T20 ve T30 değerleri (RT60, EDT, T20, and T30 values obtained from measurement Room 1)

\begin{tabular}{|l|l|l|l|l|l|l|}
\hline ODA 1 & $\mathbf{1 2 5} \mathbf{~ H z}$ & $\mathbf{2 5 0} \mathbf{~ H z}$ & $\mathbf{5 0 0} \mathbf{~ H z}$ & $\mathbf{1 0 0 0} \mathbf{~ H z}$ & $\mathbf{2 0 0 0} \mathbf{~ H z}$ & $\mathbf{4 0 0 0} \mathbf{~ H z}$ \\
\hline RT60 [s] & 0,86 & 0,80 & 0,74 & 0,71 & 0,71 & 0,70 \\
\hline EDT [s] & 0,30 & 0,12 & 0,14 & 0,10 & 0,09 & 0,09 \\
\hline T20 [s] & 0,37 & 0,24 & 0,14 & 0,16 & 0,10 & 0,11 \\
\hline T30 [s] & 0,38 & 0,26 & 0,18 & 0,15 & 0,10 & 0,10 \\
\hline C80 [dB] & 14,36 & 23,84 & 30,85 & 33,20 & 46,01 & 43,44 \\
\hline D50 [-] & 0,89 & 0,97 & 0,99 & 0,99 & 1,00 & 1,00 \\
\hline
\end{tabular}

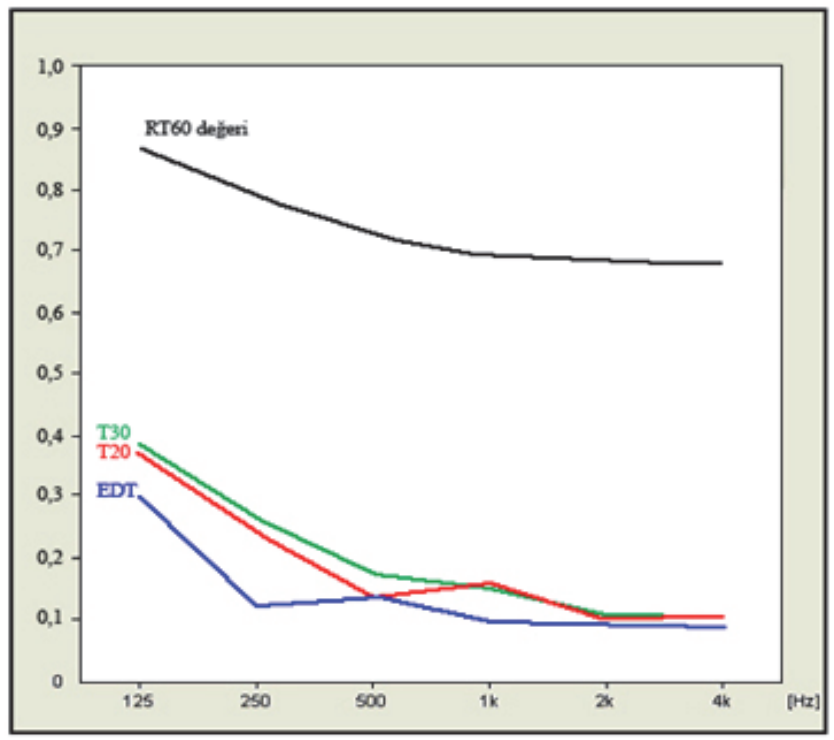

Şekil 5. "Oda 1"de elde edilen RT60, EDT, T20 ve T30 çınlama süreleri-frekans grafiği (RT60, EDT, T20, and T30 reverberation time values versus frequencies obtained from measurement Room 1)

“Oda 2"nin eni $2,85 \mathrm{~m}$, boyu 4,85 m ve yüksekliği 2,47 m'dir. Toplam hacim yaklaşık olarak $34 \mathrm{~m}^{3}$ 'tür.

Mekânın duvarlarında çeşitli girinti ve çıkıntılar mevcuttur. "Oda 2"nin duvarlarında kaplama olarak ekran arkası hariç mineral esaslı püskürtme sıva kullanılmıştır. Ekran arkasında yer alan bölümde $1,35 \times 2,50 \mathrm{~m}$ boyutlarında bir granit levha yer almaktadır. Toplam $64,15 \mathrm{~m}^{2}$ duvar yüzey alanının 30,25 $\mathrm{m}^{2}$ 'si mineral esaslı püskürtme sıva ile kaplanmıştır. Tavan yüzeylerinde $14,30 \mathrm{~m}^{2}$ alçı malzemeli asma tavan uygulaması mevcuttur. Tavanda bir girinti bulunmaktadır. Zemin de bir kot farkı vardır. Tüm zemin halı ile kaplanmıștır. Mobilya olarak bir deri koltuk bulunmaktadır (Şekil 6 ve Şekil 7) $[12]$.

Tablo 4'te "Oda 2"de kullanılan malzemeler ve yutuculuk katsayıları yer almaktadır.

\subsubsection{2 “Oda 2"deki mevcut elektronik ekipmanlar (Existing electronic equipments at Room 2)}

Philips LX710/01 Home Theatre Sistem Paketi: Bu sistem, bir ev sineması sistemi için gerekli tüm üniteleri kapsayan bir paket olarak tasarlanmıştır. Paket içerisinde bir adet merkez hoparlör, 2 adet ön hoparlör 3 adet çevreleyen hoparlör ve 1 adet bas hoparlör ile DVD/VCD oynatıcı içeren ve tüm sinema ses formatlarını (Dolby Dijital, Dolby Digital EX, Dolby Prologic II, DTS) destekleyen, alıcı özellikli bir ünite yer almaktadır.

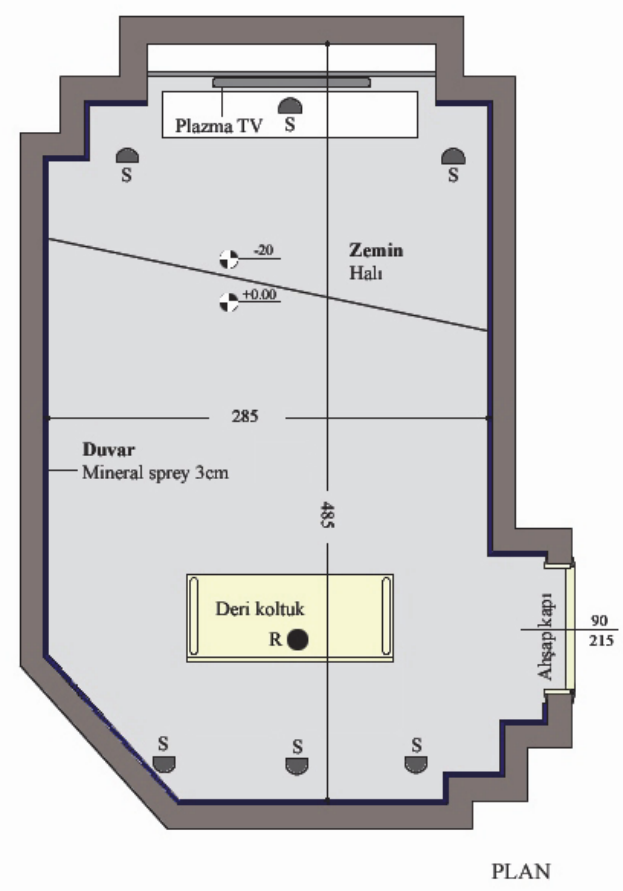

Şekil 6. "Oda 2"nin planı [12] (The plan of Room 2) 
Tablo 4. "Oda 2"de kullanılan malzemelerin yutuculuk katsayıları (The absorption co efficiency of materials in used for Room 2)

\begin{tabular}{|l|l|l|l|l|l|l|l|}
\hline Malzeme & $\mathbf{m}^{\mathbf{2}}$ & $\mathbf{1 2 5} \mathbf{~ H z}$ & $\mathbf{2 5 0} \mathbf{~ H z}$ & $\mathbf{5 0 0} \mathbf{~ H z}$ & $\mathbf{1 0 0 0} \mathbf{~ H z}$ & $\mathbf{2 0 0 0} \mathbf{~ H z}$ & $\mathbf{4 0 0 0} \mathbf{~ H z}$ \\
\hline Mineral sıva & 30,25 & 0,16 & 0,45 & 0,70 & 0,90 & 0,80 & 0,85 \\
\hline Halı & 14,10 & 0,02 & 0,06 & 0,14 & 0,37 & 0,60 & 0,65 \\
\hline Alçı asma tavan & 14,30 & 0,14 & 0,1 & 0,06 & 0,05 & 0,04 & 0,04 \\
\hline Ahşap Kap1 & 2,20 & 0,14 & 0,10 & 0,06 & 0,08 & 0,10 & 0,10 \\
\hline Deri koltuk & 1,30 & 0,40 & 0,50 & 0,58 & 0,61 & 0,58 & 0,50 \\
\hline Granit & 3,30 & 0,01 & 0,01 & 0,01 & 0,01 & 0,02 & 0,02 \\
\hline
\end{tabular}

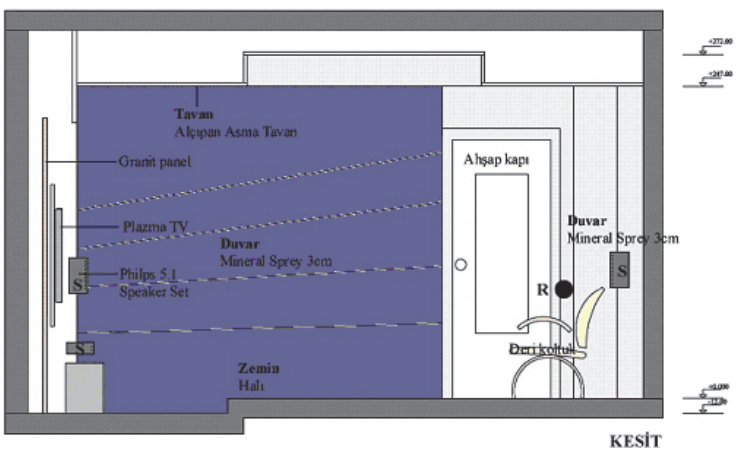

Şekil 7. "Oda 2"nin kesiti [12] (The section of Room 2)

Sistemin frekans tepkisi 200-20000 Hz arasındadır. Çıkış gücü ise $6 \times 75 \mathrm{~W}+150 \mathrm{~W}$ RMS'dir.

\subsubsection{3 Ölçüm sonuçları (Measurement results)}

“Oda 2"de yapılan deney sonucunda ölçümlenen frekanslara göre yazılımdan elde edilen çınlama süreleri Tablo 5'te verilmiştir.

“Oda 2"de elde edilen RT60, EDT, T20 ve T30 çınlama süreleri-frekans grafiği Şekil 8'de gösterilmiştir.

\subsection{3 "Oda 3" (Room 3)}

\subsubsection{Boyutsal ve geometrik analiz} (Dimensional and geometric analysis)

“Oda 3" olarak adlandırılan mekân, İzmir'in Bostanlı semtinde bir konutun yaşama odasıdır. Bu mekânda kaliteli bir ses sistemi olmasına rağmen hiçbir akustik düzenleme yapılmamıştır. Özellikle mekânda bulunan fazla cam alanı göze çarpmaktadır. Mekânın geometrisi; $3,25 \times 3,75 \times 2,65 \mathrm{~m}$ ve $3,00 \times 5,15 \times 2,65 \mathrm{~m}$ boyutlarında iki dikdörtgen prizmasının birleşmesinden oluşmaktadır. Toplam hacim 54 $\mathrm{m}^{3}$ 'tür. "Oda 3"ün duvar kaplaması sıva ve boya katmanlarından oluşmaktadır. Yaklaşık olarak 128,15 $\mathrm{m}^{2}$ yüzey alanın olduğu mekânda, $87,80 \mathrm{~m}^{2}$ sıvalı yüzey yer alırken, 11,35 $\mathrm{m}^{2}$ ahşap doğrama ve cam alanı bulunmaktadır. Cam yüzeyler önünde tül perde kullanılmıştır. Mekân zemin kaplaması halıdır. Yaşama mekânında keten kumaştan koltuklar ve ahşap mobilyalar bulunmaktadır. (Şekil 9 ve Şekil 10) [12].

Tablo 6'da “Oda 3"te kullanılan malzemeler ve yutuculuk katsayıları yer almaktadır.

\subsubsection{2 "Oda 3"teki mevcut elektronik ekipmanlar (Existing electronic equipments at Room 3)}

Ölçüm yapılan üçüncü mekânda stereo ses sistemi için iki adet hoparlör kullanılmıştır. Bu hoparlörler, ortada yer alan ekran ve kaynak cihazlarının sağ ve sol yanlarında konumlandırılmışlardır. "Oda 3"te, Triangle CELIUS Es marka ve model hoparlörler, Sony STR-DE197 $A / V$ alic1 ve Sony CDP-CE375 model CD oynatıcı ile birlikte stereo olarak düzenlenmiş olarak kullanılmaktadır. Triangle CELIUS Es Hoparlör, genelde HI-FI sistemlerde stereo ön hoparlör olarak tasarlanmıştır. $45 \mathrm{~Hz}-20$ Khz gibi geniş bir frekans aralığına sahip oldukları için oldukça ileri seviye bir müzik yayınına sahiptirler. Hoparlörün hassasiyeti $1 \mathrm{~W}, 1 \mathrm{~m}$ ölçümde $92 \mathrm{~dB}$ bir sonuç vermektedir. Hoparlörde alınacak sürekli güç $120 \mathrm{~W}$, hoparlörün verebildiği maksimum güç $240 \mathrm{~W}$ 'dır. Hoparlörün nominal direnci $8 \mathrm{Ohm}$, en düşük direnci 4 Ohm'dur.

Tablo 5. "Oda 2"nin ölçümü sonucunda elde edilen RT60, EDT, T20 ve T30 değerleri (RT60, EDT, T20, and T30 values obtained from measurement Room 2)

\begin{tabular}{|l|l|l|l|l|l|l|}
\hline ODA 2 & $\mathbf{1 2 5} \mathbf{~ H z}$ & $\mathbf{2 5 0} \mathbf{~ H z}$ & $\mathbf{5 0 0 ~ H z}$ & $\mathbf{1 0 0 0} \mathbf{~ H z}$ & $\mathbf{2 0 0 0} \mathbf{~ H z}$ & $\mathbf{4 0 0 0} \mathbf{~ H z}$ \\
\hline RT60 [s] & 0,85 & 0,79 & 0,73 & 0,70 & 0,70 & 0,69 \\
\hline EDT [s] & 0,38 & 0,48 & 0,36 & 0,27 & 0,19 & 0,12 \\
\hline T20 [s] & 0,41 & 0,58 & 0,46 & 0,29 & 0,23 & 0,20 \\
\hline T30 [s] & 0,45 & 0,54 & 0,48 & 0,37 & 0,26 & 0,21 \\
\hline C80 [dB] & 9,94 & 7,86 & 13,10 & 16,71 & 22,03 & 27,46 \\
\hline D50 [-] & 0,83 & 0,75 & 0,87 & 0,92 & 0,97 & 0,99 \\
\hline
\end{tabular}




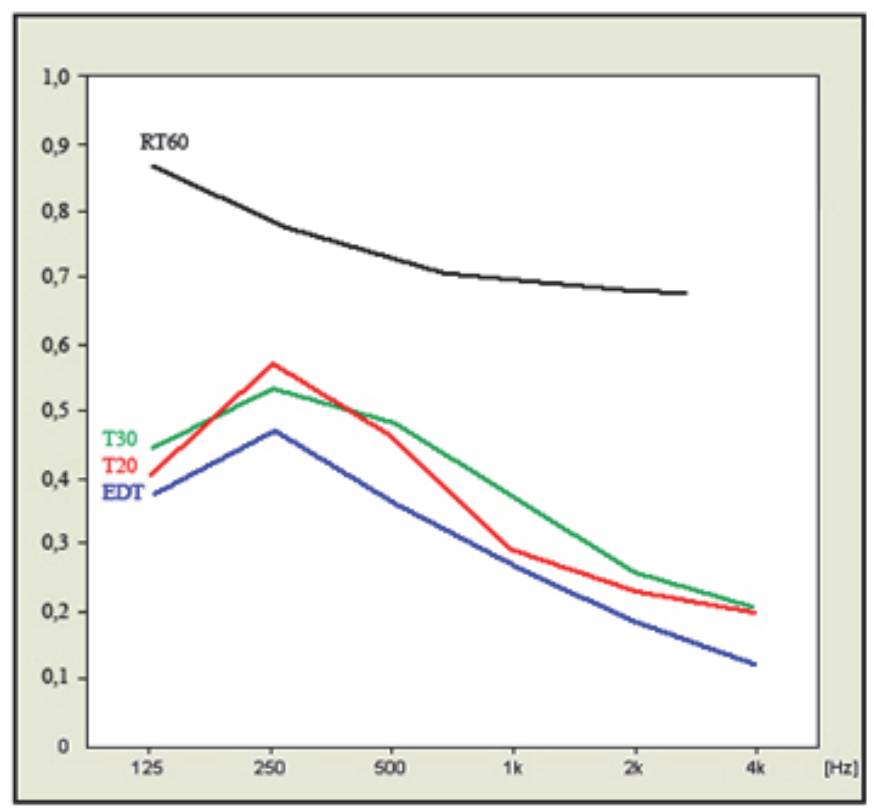

Şekil 8. "Oda 2"de elde edilen RT60, EDT, T20 ve T30 çınlama süreleri-frekans grafiği (RT60, EDT, T20, and $\mathrm{T} 30$ reverberation time values versus frequencies obtained from measurement Room 2)

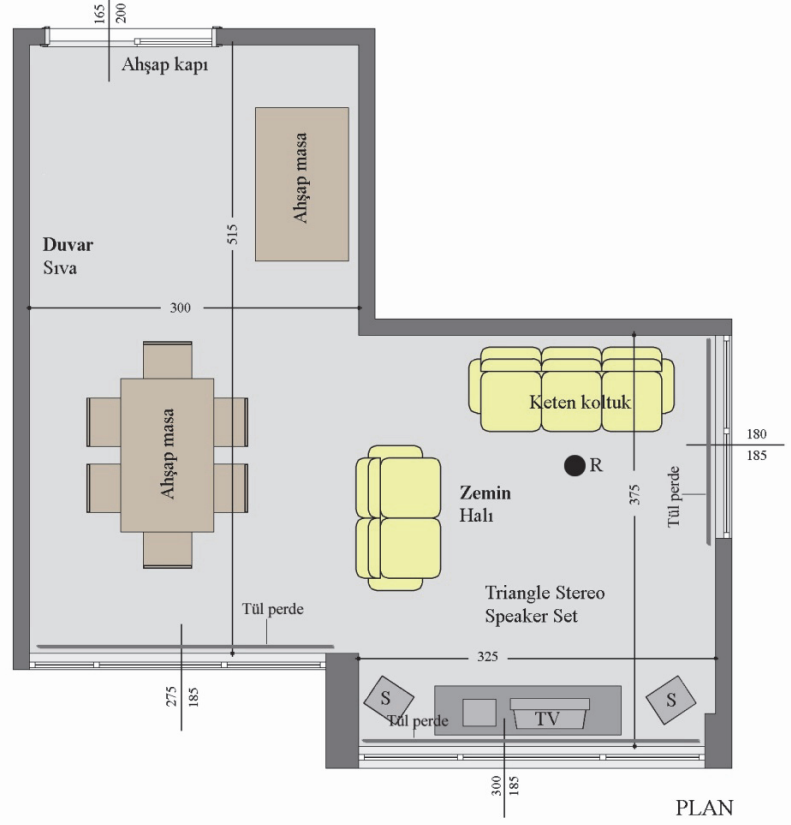

Şekil 9. "Oda 3"ün planı [12] (The plan of Room 3)

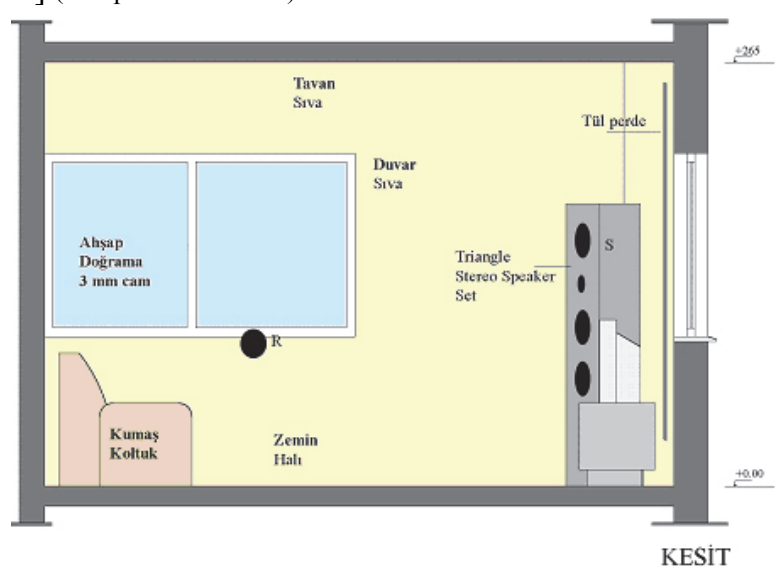

Şekil 10. "Oda 3"ün kesiti [12] (The section of Room 3) 
Tablo 6. "Oda 3"te kullanılan malzemelerin yutuculuk katsayıları (The absorption co efficiency of materials in used for Room 3)

\begin{tabular}{|l|l|l|l|l|l|l|l|}
\hline Malzeme & $\mathbf{m}^{\mathbf{2}}$ & $\mathbf{1 2 5} \mathbf{~ H z}$ & $\mathbf{2 5 0} \mathbf{~ H z}$ & $\mathbf{5 0 0 ~ H z}$ & $\mathbf{1 0 0 0 ~} \mathbf{~ z z}$ & $\mathbf{2 0 0 0} \mathbf{~ H z}$ & $\mathbf{4 0 0 0} \mathbf{~ H z}$ \\
\hline Tül perde & 18,63 & 0,03 & 0,04 & 0,11 & 0,17 & 0,24 & 0,35 \\
\hline Ahşap pencere & 11,35 & 0,35 & 0,25 & 0,18 & 0,12 & 0,07 & 0,04 \\
\hline Siva+boya & 87,80 & 0,02 & 0,02 & 0,02 & 0,02 & 0,02 & 0,02 \\
\hline Halı & 29 & 0,02 & 0,06 & 0,14 & 0,37 & 0,60 & 0,65 \\
\hline Kumaş koltuk & 3,50 & 0,49 & 0,66 & 0,8 & 0,88 & 0,82 & 0,7 \\
\hline
\end{tabular}

Tablo 7. "Oda 3" ün ölçümü sonucunda elde edilen RT60, EDT, T20 ve T30 değerleri (RT60, EDT, T20, and T30 values obtained from measurement Room 3 )

\begin{tabular}{|l|l|l|l|l|l|l|}
\hline ODA 3 & $\mathbf{1 2 5} \mathbf{~ H z}$ & $\mathbf{2 5 0} \mathbf{~ H z}$ & $\mathbf{5 0 0} \mathbf{~ H z}$ & $\mathbf{1 0 0 0 ~ H z}$ & $\mathbf{2 0 0 0} \mathbf{~ H z}$ & $\mathbf{4 0 0 0} \mathbf{~ H z}$ \\
\hline RT60 & 0,89 & 0,83 & 0,77 & 0,74 & 0,74 & 0,73 \\
\hline EDT [s] & 0,33 & 0,25 & 0,26 & 0,28 & 0,26 & 0,19 \\
\hline T20 [s] & 0,56 & 0,57 & 0,50 & 0,46 & 0,35 & 0,30 \\
\hline T30 [s] & 0,60 & 0,60 & 0,54 & 0,45 & 0,38 & 0,33 \\
\hline C80 [dB] & 10,90 & 13,87 & 15,91 & 14,39 & 15,88 & 19,67 \\
\hline D50 [-] & 0,90 & 0,93 & 0,94 & 0,91 & 0,93 & 0,95 \\
\hline
\end{tabular}

DE 197 amplifikatör 2x100 W gücü 8 Ohm yükte 40 $\mathrm{Hz}-20 \mathrm{Khz}$ aralığında ve çok düşük THD (Toplam harmonik bozunum-Total harmonic distortion) verebilecek seviyede üretilmiştir. Amplifikatör üzerinde 5 adet analog giriş mevcuttur. Amplifikatörün frekans aralığı $20 \mathrm{~Hz}-50.000 \mathrm{~Hz}$ dir. 5 CD hazneli Sony CDP-CE375 cihaz CD-R/RW oynatma kabiliyetine sahiptir.

\subsubsection{3 Ölçüm sonuçları (Measurement results)}

“Oda 3"te yapılan deney sonucunda ölçümlenen frekanslara göre yazılımdan elde edilen çınlama süreleri Tablo 7' de verilmiştir.

“Oda 3"te elde edilen RT60, EDT, T20 ve T30 çınlama süreleri-frekans grafiği Şekil 11'de gösterilmiştir.

\section{DEĞERLENDİRME VE SONUÇ (EVALUATION AND CONCLUSION OF THE CASE STUDY)}

Bu çalışmada "Oda 1", "Oda 2" ve "Oda 3"ün mekânsal özellikleri ve yapılan ölçümleme sonucunda elde edilen çınlama süreleri Tablo 8'de karşılaştırmalı olarak gösterilmektedir.

Odalarda yapılan ölçümler sonucunda $500 \mathrm{~Hz}$ 'de; “Oda 1"in RT60 değeri 0,74 s, “Oda 2"nin RT60 değeri 0,73 s ve "Oda 3"ün RT60 değeri 0,77 s olarak elde edilmiştir. Bu değerler birbirlerine yakın olmakla birlikte, çalışmanın ikinci bölümünde Şekil 2'de

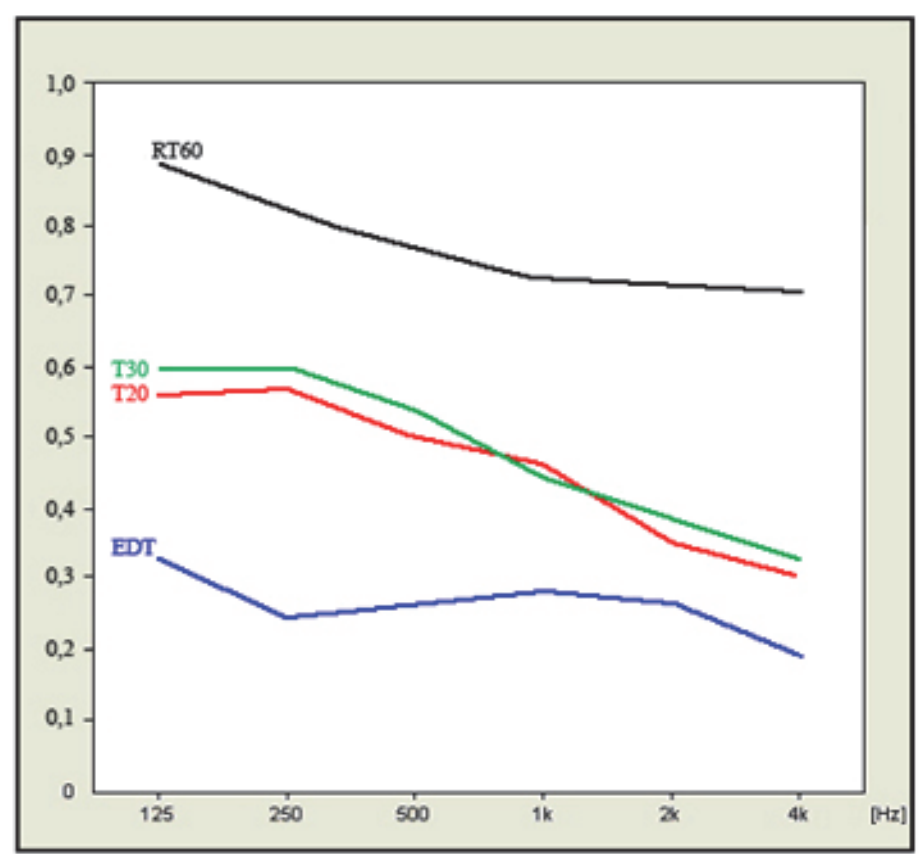

Şekil 11. "Oda 3"te elde edilen RT60, EDT, T20 ve T30 çınlama süreleri-frekans grafiği (RT60, EDT, T20, and T30 reverberation time values versus frequencies obtained from measurement Room 3) 
Tablo 8. Oda 1", "Oda 2" ve "Oda 3" için elde edilen çınlama sürelerinin karşılaştırılması (Comparison of obtained values of reverberation times for the measurement rooms.)

\begin{tabular}{|c|c|c|c|c|c|c|c|c|c|c|c|}
\hline & Plan & Kesit & $\mathrm{V}$ & Yüz.Alanı & & $125 \mathrm{~Hz}$ & $250 \mathrm{~Hz}$ & $500 \mathrm{~Hz}$ & $1000 \mathrm{~Hz}$ & $2000 \mathrm{~Hz}$ & $4000 \mathrm{~Hz}$ \\
\hline \multirow{4}{*}{ 芜 } & & & \multirow{4}{*}{ 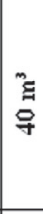 } & \multirow{4}{*}{ 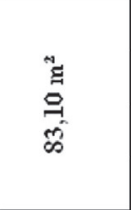 } & RT60 & 0,86 & 0,80 & 0,74 & 0,71 & 0,71 & 0,70 \\
\hline & & & & & EDT & 0,30 & 0,12 & 0,14 & 0,10 & 0,09 & 0,09 \\
\hline & & & & & $\mathrm{T} 20$ & 0,37 & 0,24 & 0,14 & 0,16 & 0,10 & 0,11 \\
\hline & & & & & T30 & 0,38 & 0,26 & 0,18 & 0,15 & 0,10 & 0,10 \\
\hline \multirow{4}{*}{ 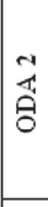 } & & & \multirow{4}{*}{ 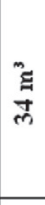 } & \multirow{4}{*}{ 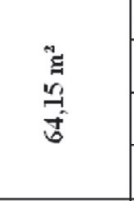 } & RT60 & 0,85 & 0,79 & 0,73 & 0,70 & 0,70 & 0,69 \\
\hline & & & & & EDT & 0,38 & 0,48 & 0,36 & 0,27 & 0,19 & 0,12 \\
\hline & & & & & $\mathrm{T} 20$ & 0,41 & 0,58 & 0,46 & 0,29 & 0,23 & 0,20 \\
\hline & & & & & T30 & 0,45 & 0,54 & 0,48 & 0,37 & 0,26 & 0,21 \\
\hline \multirow{4}{*}{ 荅 } & & 17 & \multirow{4}{*}{ 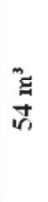 } & \multirow{4}{*}{ 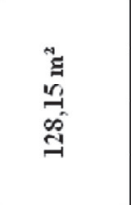 } & RT 60 & 0,89 & 0,83 & 0,77 & 0,74 & 0,74 & 0,73 \\
\hline & & & & & EDT & 0,33 & 0,25 & 0,26 & 0,28 & 0,26 & 0,19 \\
\hline & & & & & T20 & 0,56 & 0,57 & 0,50 & 0,46 & 0,35 & 0,30 \\
\hline & & & & & T30 & 0,60 & 0,60 & 0,54 & 0,45 & 0,38 & 0,33 \\
\hline
\end{tabular}

verilen $500 \mathrm{~Hz}$ 'de hacme bağlı çınlama süresi grafiğinde önerilen çınlama süreleri ile karşılaştırıldıklarında oldukça yüksektirler. "Oda 1" ve "Oda 2" arasında büyük bir hacimsel farklılık olmamasından dolayı elde edilen çınlama süreleri-RT birbirine yakındır. "Oda 3" en büyük hacme sahip olması nedeniyle diğer odalara karşılaştırıldığında en yüksek çınlama süresine sahiptir.

İdeal olarak çınlama süreleri bütün frekanslarda aynı olmalıdır. Bununla beraber düşük frekanslarda (250 $\mathrm{Hz}$ ve altı) düşük değerler elde etmek genellikle zordur [9]. Her üç örnekte de çınlama süreleri $500 \mathrm{~Hz}$ altındaki bas frekanslarda düşük frekansa doğru giderek yükselirken $500 \mathrm{~Hz}$ üzerindeki tiz frekanslarda giderek azalmaktadırlar. Odalarda kullanılan kaplama malzemeleri yüksek frekanslarda, düşük frekanslardan daha fazla yutuculuk özelliği göstermektedirler.

$\mathrm{Bu}$ bağlamda küçük hacimli mekânlarda değerlendirme kriteri olan çınlama sürelerinde ideal değerleri yakalamak için kullanılan akustik amaçlı yapı malzemelerinin miktarı ve yapısının önemi bir kez daha ortaya konmaktadır. "Oda 1" diğer iki odayla karşılaştırıldığında daha yüksek yutuculuk katsayısına sahip malzemelerle kaplanmıştır. Örneğin "Oda 1"in duvarlarında taş yünü malzeme, tavanda ise mineral esaslı püskürtme sıva kullanılmıştır. "Oda 2"de ise kullanılan kaplama malzemelerine baktığımızda yutucu amaçlı malzeme kullanımı yetersiz olmasının yanı sira ekran arkasına yerleştirilen granit levha yansıtıcı özellik göstermektedir. Ayrıca yüzey alanı yutuculuk katsayısı toplamları "Oda 2"de daha düşüktür. Tavanda kullanılan alçı malzemeli asma tavan ve duvarda kullanılan mineral sıva kaplamaları yutuculuk açısından mekânın akustiği için yetersiz kalmışlardır. "Oda 3"te yüzeylere akustik amaçlı herhangi bir yapı malzemesi yerleştirilmemiştir.
Ancak bu odada diğer örneklere kıyasla daha fazla mobilya olduğu söylenebilir. Sadece sinema odası olarak kullanılacak olan mekânlarda daha iyi sonuçlar elde etmek daha kolay ve olasıdır. Mekânda bulunan her materyalin akustik konfora etkisi olduğu düşünülürse, yaşama alanı da olarak kullanılan bir mekânda farklı işlevler ve eşya fazlalığı gibi durumlarda belli başlı sorunlar oluşabilmektedir.

Çalışmanın önceki bölümlerinde belirtildiği gibi küçük hacimli mekânlarda modal rezonanslar akustik açıdan bir başka önemli değerlendirme kriteridir. Bu mekânların modal rezonanslar açısından değerlendirilmesi üzerine yapılan çalışmalar oda oranları üzerine temellendirilmiştir. Ev sineması mekânının tasarımı aşamasında, plansal düzlemde, modal rezonansları engellemek için araştırmalar sonucunda elde edilen oda oranlarından biri seçilmeli veya var olan bir mekânı bu oranlara getirmeye çalışılmalıdır. En ideal form dikdörtgen planlı mekânlardır. Örnek odalar bu bağlamda incelendiğinde, “Oda 1" ve “Oda 2"nin geometrik biçimi dikdörtgen prizmaya yakındır. "Oda 3" için söylenebilecek ilk şey mekân geometrisinin ilk iki odadan farklı olduğudur. "Oda 3" ev sineması mekânı olarak tasarlanmamıştır. "L" plan şemasına sahip bu mekân akustik açıdan iki ayrı mekân gibi değerlendirilebilir. Bu mekândaki ev sineması sistemi, birbirine bağlı iki adet dikdörtgen alanın bir tanesinde yer almaktadır. Dinleme noktasının bulunduğu yer aslında tüm mekânın akustik özelliklerini değil kendi küçük alanının akustik özelliklerini taşımaktadır. Ancak mekândaki plansal sorunlar akustik açıdan istenmeyen sonuçları beraberinde getirebilmektedir.

Ev sinemasının akustik konforunu etkileyen bir diğer etken elektronik ekipmanların kalitesidir. Sesin kalitesi, seçilen sistemin kalitesine bağlı olarak pozitif yönde bir gelişme sağlayacaktır. Günümüzde değişen teknolojik şartların paralelinde gelişen bir sektör olan 
ses sistemleri de belli standartlara oturmaya başlamıştır. Elektronik ekipman seçiminde öncelikle hacim göz önüne alınmalıdır. Çok küçük boyutlarda bir hacim için çok güçlü RMS değerlerine sahip ekipmanlar seçilmesi mekânda istenmeyen etkilere sebep olmaktadır. Elektronik materyal seçiminde stereo veya çevreleyen ses sistemi seçimine göre yerleşim planı yapılmalıdır. Çevreleyen ses-surround sound sistemlerinin mekân içindeki yerleşiminde en önemli unsur çevreleyen-surround etkisini verecek konumlandırmayı sağlamaktır.

Sonuç olarak, incelenen örneklerde bir ev sineması için gerekli akustik önlemler yeterince alınmamıştır. İncelenen odaların geometrik ve mekânsal özellikleri ve bu mekânlarda kullanılan yutucu malzeme miktarları ve seçimleri yetersizdir. Kullanılan elektronik akustik sistemler ile odaların akustik kusurları giderilmeye çalışılmıştır. $\mathrm{Bu}$ nedenle, bir mekânı tasarlarken ve özellikle bu mekâna ev sineması fonksiyonu yüklerken, bu işlemin detaylarının başlangıçta çok iyi düşünülmesi gerekmektedir. Özellikle kapalı mekânlarda işin içinde elektronik ekipmanların da olduğunu göz önüne alırsak, iyi bir akustik için bütün elemanların birbirine entegre biçimde olması gereklidir. Çok pahalı bir ses sistemi akustik düzenlemesi hiç yapılamamış bir mekânda gerçek performansını sağlayamayacaktır. Bunun tam tersi olarak da daha düşük değerde bir ses ekipmanı çok iyi düşünülmüş bir akustik düzenlemeye sahip kapalı bir mekânda beklenenin üstünde performans sergileyebilecektir.

\section{KAYNAKLAR (REFERENCES)}

1. Hull, J., "Surround Sound", Handbook for Sound Engineers, Cilt 6, Editör: Ballou, G., Focal Pres, New York, A.B.D., 1453-1463, 2002.

2. Cavanaugh, W.J. ve Wilkes J.A., Architectural Acoustics: Principles and Practice, Editör: Cavanaugh, W.J., John Wiley and Sons Inc., New York, A.B.D., 1999.

3., ISO 3382-1, Acoustics-Measurement of Room Acoustic Parameters-Part 1: Performance Spaces, International Organization for Standardization (ISO), 2009.

4. Göksel, G., "Surround Sound-I", Broadcasterinfo, Cilt 1, No 6, 104-107, 2004.

5. Derry, R., "Introduction of Digital Audio", Audio Engineer's Reference Book, Cilt 1, Editör: Smith, M.T., Taylor \& Francis, New York, A.B.D., 98-105, 2001.

6. Göksel, G., "Surround Sound-II", Broadcasterinfo, Cilt 2, No 7, 158-162, 2004.

7. Fleischmann, M., Practical Home Theater: A Guide to Video and Audio Systems, Quiet River Press LLC., New York, A.B.D., 2012.

8. Everest, F.A., Master Handbook of Acoustics, McGraw-Hill Companies, New York, A.B.D., 2001.

9. Cowan, J., Architectural Acoustics Design Guide, McGraw Hill, New York, A.B.D., 2000.

10. Mehta, M., Johnson, J. ve Racafort, J., Architectural Acoustics Principles and Design, Prentice-Hall Inc., New York, A.B.D., 1999.

11. Long, M., Architectural Acoustics, Elsevier Academic Press, A.B.D., 2006.

12. Sağın, S.M., Ev Sineması Sistemlerinde Mekân Akustiğinin İrdelenmesi, Yüksek Lisans Tezi, Dokuz Eylül Üniversitesi, Fen Bilimleri Enstitüsü, 2005 . 
